\title{
PERANAN PEMERINTAH DESA DALAM PEMBANGUNAN INFRASTRUKTUR
}

\author{
Yoga Hariyanto ${ }^{1}$, Shulis ${ }^{2}$, Figur Adhiyakam ${ }^{3}$ \\ ${ }^{1}$ SMA Negeri 4 Pontianak, Kalimantan Barat, Indonesia. \\ e-mail korespondensi: figuradhiyakam@gmail.com
}

\begin{abstract}
Abstrak : Penelitian ini bertujuan untuk mendeskripsikan pembangunan infrastruktur yang ada di desa Kalimas, Kec. Sungai kakap, Kab. Kubu raya. Desa Kalimas merupakan salah satu desa di Kecamatan Sungai Kakap Kabupaten Kubu Raya. Desa Kalimas memilik luas wilayah 4.565 ha dengan rincian perkampungan (711 ha), perkebunan (2185 ha), perkarangan (239 ha), tanah pertanian (1370 ha) dengan luas wilayah tersebut maka masyarakat kebanyakan bekerja pada bidang pertanian. Dalam penelitian ini penulis menggunakan jenis penelitian deskriptif dengan pendekatan kualitatif. Teknik pengumpulan data dengan observasi, wawancara dan dokumentasi. Berdasarkan hasil penelitian yang telah dilakukan dapat disimpulkan bahwa pemerintah desa Kalimas telah berhasil melakukan pembangunan infrastruktur seperti pembangunan jembatan, jalan, pengadaan fasilitas pemadam kebakaran, poskamling dan mobil ambulance. Akan tetapi sejak pandemi covid-19 mewabah di indonesia, pembangunan infrastruktur di desa kalimas menjadi terhambat karena Dana Desa (DD) dialihfungsikan untuk membantu masyarakat yang terdampak covid-19..
\end{abstract}

Kata kunci: Pembangunan, Peranan Pemerintah Desa, Infrastruktur

\begin{abstract}
This study refers to construction in the village of Kalimas, Sungai Kakap sub district, Kubu Raya district. The village of Kalimas covers a territory of 4565 acres with village detail (711 ha), estates (2185 ha), halview (239), land agriculture (1370 ha) with such an area of territory, the masses of communities mostly harnessed themselves. In this study writers use types of descriptive research with a qualitative approach. Data collection techniques with obsenation, interviews, and documentaries based on research conducted, it was concluded that the village government of kalimas has managed to build infrastructure such as the construction of road, bridge, the procutiens of fire facilities, the post and ambulance. It will remain permanently eroded the covid-19 pandemic in Indonesia, building infrastructure in the village of kalimas is banned because rural funds are being diverted to help stranded communities.
\end{abstract}

Keyword: Development, the role of village government, infrastructure

\section{PENDAHULUAN}

Desa adalah kesatuan masyarakat hukum yang memiliki batas wilayah yang berwenang untuk mengatur dan mengurus urusan pemerintahan. Kepentingan masyarakat setempat berdasarkan prakarsa masyarakat, hak asal usul, dan/atau hak tradisional yang diakui dan dihormati dalam system pemerintahan Negara Kesatuan Republik Indonesia. (UU RI Nomor 6 Tahun 2014).Dengan wewenang tersebut maka pemerintah desa memiliki tanggungjawab dalam mengatur masyarakat, melayani masyarakat serta melakukan upaya pembangunan di desa melalui kesepakatan bersama dengan masyarakat. Ginandjar Kartasasmita (2015: 392), Pembangunan pedesaan dalam arti luas mencakup berbagai bidang kehidupan seperti ekonomi, sosial, budaya, politik dan keamanan yang mengintegrasikan peran pemerintah dan 
masyarakat dalam pengelolaannya dengan memanfaatkan sumberdaya pembangunan secara efektif guna peningkatan kualitas hidup dan kesejahteraan masyarakat secara berkesinambungan.

Infrastruktur pada dasarnya merupakan aset pemerintah yang dibangun dalam rangka pelayanan terhadap masyarakat. Prinsipnya ada dua jenis infrastruktur, yakni infrastruktur pusat dan daerah. Pembangunan infrastruktur di desa Kalimas cukup baik dan pemerintahan desa juga selalu mengadakan musyawarah sebelum dilakukannya pembangunan guna untuk mengetahui kebutuhan masyarakat agar pembangunan yang dilakukan sungguh bermanfaat bagi masyarakat.

Pada dasarnya pembangunan memiliki tujuan agar terciptanya kualitas kehidupan masyarakat yang lebih baik serta menciptakan kesejahteraan bagi masyarakat tersebut. Sebagaimana Tujuan Pembangunan Desa (Ps 78 UU Desa), yakni untuk Meningkatkan Kualitas Hidup Manusia, Meningkatkan Kesejahteraan Masyarakat Desa, dan Penanggulangan Kemiskinan.

Desa Kalimas merupakan salah satu desa di Kecamatan Sungai Kakap Kabupaten Kubu Raya. Desa Kalimas memilik luas wilayah 4.565 ha dengan rincian perkampungan (711 ha), perkebunan (2185 ha), perkarangan (239 ha), tanah pertanian (1370 ha) dengan luas wilayah tersebut maka masyarakat kebanyakan bekerja pada bidang pertanian, meskipun demikian disamping bertani ada juga yang berprofesi sebagai buruh, wiraswasta, dan juga yang menjadi PNS, TNI/POLRI namun sangat sedikit sekali. Secara administratif Desa Kalimas terdiri dari lima dusun (Dusun Cempaka, Dsusun Melati, Dusun Anggrek, Dusun Mawar dan Dusun Beringin) dengan 12 RW DAN 40 RT, dengan jumlah penduduk berdasar sensus tahun 2011 sebanyak 6649 jiwa dengan perincian 3430 orang laki-laki dan 3219 orang perempuan.

Penelitian ini betujuan untuk menganalisis pembangunan infrastruktur yang ada di desa Kalimas, Kec. Sungai Kakap, Kab. Kubu Raya. Dalam penelitian ini didapatkan sebuah fakta bahwa pembangunan infrastruktur di desa Kalimas menjadi terhambat akibat pandemi covid-19. Hal ini disebabkan Dana Desa (DD) dialihfungsikan untuk membantu masyarakat yang terkena dampak covid-19.

\section{METODE}

Penelitian ini menggunakan pendekatan deskriptif kualitatif, menurut Nazir (1988, h.63) metode deskriptif adalah suatu metodologi dalam meneliti suatu kelompok manusia, suatu objek ,suatu set kondisi, suatu sistem pemikiran ataupun suatu luas pemikiran pada masa sekarang.

Menurut Koentjaraningrat (1990, h.29) bahwa penelitian yang bersifat kualitatif bertujuan untuk menggambarkan secara tepat sifat-sifat suatu individu, keadaan, gejala atau kelompok tertentu dan atau untuk menentukan frekuensi atau penyebaran suatu gejala dalam masyarakat. Fokus dalam penelitian ini adalah: (1)Dampak pembangunan infrastruktur bagi masyarakat (2) Peranan pemerintah desa dalam pembangunan infrastruktur di desa kalimas (3) Faktor penghambat peembangunan infrastruktur di desa Kalimas.

\section{HASIL DAN PEMBAHASAN \\ Dampak Pembangunan Infrastruktur}

Pembangunan atau "development" adalah upaya sadar dan sistematis dari pemerintah dalam upaya meningkatkan kualitas kehidupan yang lebih baik bagi masyarakat serta upaya meningkatkan kesejahteraan bagi masyarakat itu sendiri. Pembangunan adalah upaya berkesinambungan menciptakan keadaan yang dapat menyediakan lebih banyak alternatif yang sah (valid) bagi setiap warga negara untuk mencapai aspirasinya yang paling humanistik. Pada umumnya, aspirasi yang paling humanitsik tersebut dinyatakan sebagai peningkatan kesejahteraan masyarakat (society uelfare).

Desa Kalimas merupakan salah satu desa di Kecamatan Sungai Kakap Kabupaten Kubu Raya. Desa kalimas juga merupakan salah satu desa yang sedang mengalami pembangunan. Pembangunan yang terjadi di desa ini baru mulai benar-benar digalakkan pada tahun 2006. Pembangunan yang ada didesa kalimas dilakukan dibanyak titik. Setiap tahunnya terdapat pembangunan dengan menggunakan Anggaran Dana Desa. Fokus pembangunan bukan hanya pada infrastruktur seperti jembatan dan jalan saja. Namun juga pada peningkatan kapasitas BPD dan pemberdayaan masyarakat seperti; PKK, Karang Taruna, 
bidang Kesenian dan juga berbagai keperluan lain dalam lingkup desa.

Pembangunan pada hakikatnya adalah perubahan yang terencana dari situasional yang satu ke situasional yang lain yang dinilai lebih baik (Katz dalam Supriatna, $2000: 28$ ). Menurut Bryan and White (1989 : 21) pembangunan diartikan sebagai peningkatan kemampuan orang untuk mempengaruhi masa depannya.

Pembangunan secara sederhana diartikan sebagai suatu perubahan tingkat kesejahteraan secara terukur dan alami. Perubahan tingkat kesejahteraan ditentukan oleh dimensi dari definisi ekonomi, sosial, politik, atau hukum. Perubahan terukur ditentukan oleh dimensi perubahan itu dalam definisi ekonomi, sosial, politik, atau hukum. Perubahan alami ditentukan oleh siapa yang berperan dalam perubahan itu. Perubahan alami adalah perubahan yang melembaga dalam bangun sosial sekelompok manusia. Hanya perubahan alami yang mampu menjamin adanyaperubahan terukur secara konsta. (Randy R. Wrihatnolo rian D. Nugroho 2006).

Adapun dampak Pembangunan
Infrastruktur Bagi Masyarakat Desa Kalimas adalah sebagai berikut:

Secara garis besar masyarakat Kalimas pada umumnya merasakan dampak baik dari pembangunan yang ada seperti contoh pembangunan jalan yang bisa memudahkan masyarakat dalam bertransportasi sehingga masyarakat mudah dalam melakukan kegiatan ekonomi seperti berdagang dan juga pembangunan jalan yang ada di desa kalimas dapat meminimalisir banjir karena ketinggian jalan di tambah kapasitasnya. Selain pembangunan jalan, di desa kalimas juga tersedia fasilitas seperti pemadam kebakaran dan ambulance. Dengan adanya fasilitas pemadam kebakaran setidaknya mengurangi kekhawatiran masyarakat terhadap kebakaran. Ketersediaan ambulance juga sangat membantu masyarakat desa kalimas dimana sebelum adanya ambulance masyarakat harus menggunakan kendaraan seperti mobil pick-up untuk membawa pasien ke rumah sakit besar yang ada di ibu kota kecamatan. Jadi dapat disimpulkan bahwa ketersediaan fasilitas pembangunan yang ada di desa Kalimas sangat berdampak baik bagi masyarakat di desa kalimas.

\section{Peranan Pemerintah Desa Kalimas dalam Pembangunan Infrastruktur}

Pemerintah Desa Kalimas memiliki peranan yang penting dalam pengelolaan dana desa demi pembangunan desa. Menyangkut masalah pembangunan, di desa kalimas menggunakan ADD (Anggaran Dana Desa) dalam memenuhi anggaran. Dalam memtuskan pembangunan apa saja yang harus dilakukan dengan efektif dan efisien awal mula nya Pemerintah Desa Kalimas melakukan musawarah dusun.

Sebelum dana pembangunan desa itu diluncurkan Pemerintah Desa Kalimas melakukan kunjungan disetiap dusun. Dalam hal ini Pemerintah Desa Kalimas akan menggali informasi dari setiap kepala dusun dan aspirasi dari masyarakatnya terlebih dahulu tentang apa yang akan dilakukan atau apa yang perlu dibangun. Dan tak lupa juga melakukan survey atau melihat tempat yang perlu dibangun.

Setelah dilakukan musyawarah Pemerintah Desa Kalimas akan mendapatkan gambaran tentang apa yang harus dibangun maka terbentuklah RPJMDES (Rencana Kegiatan Pembangunan Desa). Hal ini bertujuan guna menjangkau pembangunan untuk beberapa tahun kedepan. Setelah itu, Pemerintah Desa Kalimas hanya tinggal menyesuaikan saja mengenai kebutuhan masyarakat tentang infrastruktur atau fasilitas yang akan dibangun atau diadakan.

Pemerintah desa akan memprioritaskan kebutuhan yang lebih penting dan tidak mengikuti keinginan masyarakat yang tidak sesuai dengan kebutuhan. Seluruh kegiatan yang dilakukan demi pembangunan desa ini tidak lepas dari musyawarah dusun, musyawarah desa, dan musyawarah rencana pembangunan. Setelah itu dibentuklah semacam RKP (Rencana kerja Pemerintah). Sehingga setelah jelas atau ditetapkan infrastruktur apa yang akan dibangun maka tinggal dilakukan realisasi atau pembangunan secara nyata.

Pemerintah desa kalimas memfokuskan lebih banyak pada pembangunan infrastruktur guna penunjang kelancaran aktivitas masyarakat dalam bermitra dan berniaga baik didalam desa maupun di luar desa. Hal ini juga menjadi dampak baik bagi pedagang kecil di desa kalimas. Pemerintah desa juga mengupayakan pembangunan pada sektor 
Volume 12 | Number 1| April |2021, Page 24-29/ E-ISSN: 2715-1247 dan P-ISSN: 2087-84xx

pemberdayaan masyarakat dengan membangun kembali budaya yang dulunya hilang di tengah masyarakat. pemerintah berkoordinasi dengan dinas sosial untuk mengembalikan lagi budayanya salah satunya tari zapin yang pernah mewakili kalbar.Pemerintah desa juga menciptakan pola komunikasi yang baik kepada masyarakat dengan cara berbaur kembali dengan masayarakat menanyakan permasalahan yang ada ditengah masyarakat agar bisa dicarikan proses penyelesaiannya.

Peranan (Dahlan, 1999:5) berasal dari kata peran. Peran mempunyai arti perilaku atau, pemain atau bertindak. Sedangkan peranan mempunyai arti fungsi, kedudukan atau bagian kedudukan. Selanjutnya Siagian (1981:21) mengemukakan bahwa "Peranan adalah tempat tertentu yang ditentukan untuk diduduki oleh seseorang dalam suatu proses pencapaian tujuan.

Sedangkan pembangunan menurut Siagian (2000:15) adalah rangkaian usaha mewujudkan pertumbuhan dan perubahan yang berencana yang dilakukan secara sadar yang ditempuh oleh suatu Negara dan pemerintah menuju modernitas dalam rangka pembinaan bangsa (Nation Building). Pendapat lain dikemukakan oleh Todaro (2000:20) bahwa "Pembangunan adalah proses multi dimensi yang mencakup perubahanperubahan penting dalam struktur sosial, sikap-sikap rakyat dan lembagalembaga nasional, dan juga akselerasi pertumbuhan ekonomi, pengurangan kesenjangan dan pemberantasan kemiskinan absolute".

Dalam proses pembangunan di desa kalimas, pemerintah desa melakukan musyawarah terlebih dahulu bersama masyarakat. Hal ini dilakukan agar memudahkan dalam memprioritaskan pembangunan yang akan dilakukan berdasarkan keputusan musyawarah bersama.

\section{Hambatan Dalam Pembangunan}

Menurut Kamus Besar Bahasa Indonesia (2002: 385) hambatan adalah halangan atau rintangan.Hambatan memiliki arti yang sangat penting dalam setiap melaksanakan suatu tugas atau pekerjaan. Suatu tugas atau pekerjaan tidak akan terlaksana apabila ada suatu hambatan yang mengganggu pekerjaan tersebut. Hambatan merupakan keadaan yang dapat menyebabkan pelaksanaan terganggu dan tidak terlaksana dengan baik.Setiap manusia selalu mempunyai hambatan dalam kehidupan sehari-hari, baik dari diri manusia itu sendiri ataupun dari luar manusia.

Dalam proses pembangunan akan ada hal yang menjadi penghambat. Begitu juga dengan pembangunan di desa Kalimas. Semenjak mewabahnya pandemi covid-19 yang muncul pada akhir tahun 2019 maka berdampak pada pembangunan di desa Kalimas. Hal ini disebabkan oleh penggunaan DD (Dana Desa) dialihfungsikan untuk membantu masyarakat yang terkena dampak covid-19.

\section{Hasil wawancara ke masyarakat di desa Kalimas}

a. pembangunan yang terjadi selama beberapa tahun terakhir didesa kalimas. Pembangunan benar- benar baru digalakkan pada tahun 2006. Desa juga membanatu masyarakat pada bidang kesenian. Terdapat pembangunan setiap tahunnya dengan menggunakan ADD (Anggaran Dana Desa), fokus pembangunan bukam hanya pada infrastruktur seperti jembatan namun juga pada peningkatan kapasitas bpd,pkk, karang taruna, bdang kesenian dan juga berbagai keperluan dalam lingkup desa. Pembangangunan tetap ada tiap tahunnya misalnya jembatan, jalan, poskamling, penyediaan genset atau pembangkit liistrik darurat, ambulance, sudah ditentukan dan disiapkan dana untuk menunjang proses pembangunan infrastruktur desa. Dikarenakan terkena dampak covid proses pembangunan infrastruktur jadi terhambat dikarenakan dana desa digunakan untuk membantu masyrakat yang terdampak covid. Masyarakat tidak diperkenankan untuk membantu pemerintah desa di bagian finansial. Jika pun ada masyarakt yang ingin membanatu secara finansial dana tersebut akan dipisahkan atau tidak boleh dicampur-adukkan dengan dana dari desa dan pemerintah. walaupun dana desa belum sepenuhnya bisa membantu proses pembangunan infrastruktur namun pemerintah desa tetap mengupayakan pembangunan infrastruktur demi kenyaman dan keamanan masyarakat desa.

b. respon masyarakat terhadap pembangunan yang terjadi. Secara garis besar hasil dari 
wawancara ke masyarakat bahwa mereka merasakan dampak baik dari dibangunnya infrastruktur desa berupa jalan bisa memudahkan masyarakat dalam bertransfortasi. Masyarakat tidak lagi merasa takut akan bahaya banjir yang melanda desa tersebut. Bagi masyarakat yang membuka usaha dengan adanya pembangunan tersebut dapat mempermudah akses pelanggan. Selain itu juga terdapat penyediaan fasilitas berupa pemadam kebakaran dan juga ambulance. Dengan adanya fasilitas pemadam kebakaran setidaknya mengurangi kekhawatiran masyarakat terhadap kebakaran. Untuk penyediaan fasilitas ambulance masyarakat yang akan melahirkan akan diantar menggunakan ambulance tersebut.

c. kehidupan religius, sosial, dan ekonomi masyarakat di desa ini untuk hubungan pemerintah desa dengan masyarakat untungnya sangat baik.karena kita melakukan beberapa hal dalam melakukan pendekatan baik itu dalam bidang sosial, bidang keagamaan, kita aka selalu hadir untuk menyatukan diri kita dengan masyarakat. Kenapa demikian? Karena dengan dukungan masyarakatlah desa kita pemerintahannya bisa bergerak. Contohnya misalnya ada suatuu acara yang dilaukan oleh masyarakat kadang-kadag ada atau tidaknya undngan kami tetap datangmaupun itu acara maulid ataupun kematan kami menyempatkan diri untuk hadir sebagai rasa menyatu sebagai masyarakat desa. Kami sebagai pemerintah desa juga ingin berbaur dan menggali mengenai masyarakat yang kurang terkordinir dari RT atau RW karena kadangkan banyak masyarakat yang takut atau malas ke kantor. Dengan turun kelapangan inilah kami mencari infomasi. Jadi sistemnya di 2020-2021 ini adalah menjemput bola (misalnya ada msyarakat yang tidak mempunyai kk, ktp, ssilahkan diberitahu kepada rtny) yang ada dibawah sekaigus menggali aspirasi masyarakat. Dan jua memberika informasi terkadang di dalam acara pengajian juga kita selalu menghimbau tolong dilengkapi administrasi yang diperlukan. Apa lagi yang mau nikah, jangan pula pada waktu mau melahirkan baru besibok ngurus administrasi. Mengeai gotong rotong"terkadang kepala desa dan perangat desa juga ikut gotong royong bersama masyarakat dan rt rw. Itu sebagai ukti kami mendekatkan diri kepada msyarakat"

d. pengelolaan dana desa oleh pemerintah desa. Menyangkut masalah dana awal mula nya pemerrintah desa melakukan musawarah dusun. sebelum dana itu diluncurrkan kami melakukan kunjungan disetiap dusun dan kami menggali aspirasi masyarakat terlebih dahulu tentang apa yang akan dilakukan dan dibangun. Setelah dilakukan kami mendapatkan gambaran tentang apa yang akan dibangun maka terbentuklah RPJMDES (rencana kegiatan pembangunan desa) guna menjangkau pembangunan untuk lima tahun kedepan tinggal menyesuaikan saja mengenai kebutuhan masyarakat dan tidak mengikuti keinginan masyarakat yang tidak sesuai dengan kebutuhan. Dan hal itu tidak lepas dari musyawarah dusun, musyawarah desa, dan musyawarah rencana pembangunan lalu dibentuklah semacam RKP. Jadi intinya musyawarah terlebih dahulu.

e. Kehidupan budaya masyarakat desa kalimas. Budaya yang masih ada disini yaitu tari bali, tondang seperti pantunpantun, marawis, hadra. Saya juga berkeinginan dan berkoordinasi dengan dinas sosial untuk mengembaalikan budaya kalimas pada 1984 yatu tari zapin yang pada waktu itu mewakili Kalimantan Barat.

f. Mata pencaharian masyarakat sebagian besar petani; petani padi, petani sayur, perkebunan terus adaa juga yang bekerja swasta dan tukang. Namun mungkin $70 \%$ petani di desa ini.

g. Diadakan Kegiatan majelis taklim dan PKK, karang taruna mengadakan kegiatan guna mengumpulkan dana untuk masyarakat yang kurang mampu didesa tersebut. 


\section{SIMPULAN}

Desa kalimas adalah salah satu desa yang sedang mengalami pembangunan baik sumber daya maupun infrastuktur. Pemerintah Desa Kalimas memiliki peranan yang penting dalam pengelolaan dana desa demi pembangunan desa. Pemerintah desa akan memprioritaskan kebutuhan yang lebih penting dan tidak mengikuti keinginan masyarakat yang tidak sesuai dengan kebutuhan desa. Dalam proses pembangunan desa kalimas untuk sementara waktu terhambat karena dampak covid 19. Hal ini membuat dana desa yang tadinya sebagai faktor pendukung pembangunan desa beralihfungsi sebagai sarana untuk membantu kebutuhan materil masyarakat yang terdampak covid.

\section{DAFTAR RUJUKAN}

Ajeng Dini Utami. 2019. Buku Pintar Pemberdayaan Masyarakat Desa Yogyakarta: Desa Pustaka Indonesia.

Akib, Karmila dan Tepare,Olfi Alfionita. 2017. Peranan Pemerintah Desa Dalam Pembangunan Infrastruktur Jalan Di Desa Malitu Kecamatan Poso Pesisir Selatan Kabupaten Poso. Jurnal Ilmiah Administratie 8

Biamding, Hariawan. 2019. Perencanaan Pembangunan Partisipasif Desa. Sleman: CV. Budi Utama

Dewi, Selviana dan Ichwan Prastowo. 2019. Peranan Business Center Dalam Menanggulangi Hambatan Pada Sektor Pendapatan Front Office Department Di Lorin Solo Hotel. Surakarta. Journal Politeknik Indonusa Surakarta ISSN : 2442$7934: 5$
Dilahur. 1994. Geografi Desa Dan Pengertian Desa. Forum Geografi No. 14 dan 15 Th. VIII.

Jamaludin, Adon Nasrullah. 2016. Sosiologi pembangunan. Bandung: CV Pustaka Setia.

Mahi, Ali Kabul Dan Trigunarso, Indra Sri. 2017. Perencanaan Pembangunan Daerah Teori dan Aplikasi. Jakarta: KENCANA

Mardhiah, Nellis. 2014. Identifikasi Tujuan Dan Sasaran Pembangunan Desa Kabupaten Aceh Barat. Jurnal Public Policy 1

N. Daldjoeni, 1987. Interaksi DesaKota.Jakarta: Rineka Cipta.

R. Wrihatnolo, Randy dan Nugroho D., Rian. (2006). Manajemen Pembangunan Indonesia sebuah pengantar dan panduan. Jakarta: Pt. Elex Media Komputindo.

Revida, Erika dkk. 2020. BUMDES; Menuju Optimalisasi Ekonomi Desa. Medan : Yayasan Kita Menulis

Soleh Ahmad. 2017. Strategi Pengembangan Potensi Desa. Jurnal Sungkai Vol.5 No.1

Ulumiyah, Ita, DKK. 2013. Peran Pemerintah Desa Dalam Memberdayakan Masyarakat Desa. Jurnal Administrasi Publik (JAP), Vol. 1, No. 5, Hal. 890-899 ${ }^{6}$

Wardiyanto Bintoro, dkk. (2016). Percikan pemikiran tata kelola dan pembangunan. Surabaya: Airiangga University Press. 454 hlm

Zamzami, Fauzani. 2014. Analisis Pengaruh Infrastruktur Terhadap Pdrb Jawa Tengah Tahun 2008 - 2012. Skripsi. Fakultas Ekonomika dan Bisnis Universitas Diponegoro. 